\title{
Learners' Perceptions of Monolingual Dictionaries in Learning English as a Foreign Language
}

\author{
Wajahat Taj Abbasi ${ }^{1 *}$, Mudassar Mahmood Ahmad², Faiza Abdalla Elhussien Mohammed ${ }^{3}$ \\ ${ }^{1}$ Majmaah University, Saudi Arabia \\ ${ }^{2}$ Royal Commission College and Institute Yanbu, Saudi Arabia \\ ${ }^{3}$ College of Education, Majmaah University, Saudi Arabia
}

Corresponding author: Wajahat Taj Abbasi, E-mail: safwanabbasi2010@yahoo.com

\begin{tabular}{l} 
ARTICLE INFO \\
\hline Article history \\
Received: Auguest 30, 2018 \\
Accepted: June 07, 2019 \\
Published: July 31, 2019 \\
Volume: 7 Issue: 3 \\
\hline
\end{tabular}

Conflicts of interest: None Funding: None

\begin{abstract}
Dictionary is an acknowledged learning tool which has a tremendous role in acquiring a language. It has proved to be helpful in learning vocabulary and developing language proficiency. The use of monolingual dictionaries is thought to be very fruitful for learning vocabulary. The present study used survey method to gain the perception of the students about the use of monolingual dictionaries for learning EFL. The study also used interviews of EFL teachers to support the findings of the study by eliciting their perceptions about the use of dictionaries by students. A questionnaire was administered in two governmental secondary schools of Zulfi, Saudi Arabia. It was sent to 99 students but a number 92 students responded. Internal reliability of the questionnaire was.81. Descriptive statistical methods were used for analyzing the quantitative data. Additional interviews with 9 teachers were also conducted to support the findings of the questionnaire. Collective thematic analysis of all interviews was conducted to analyze the qualitative data. The results showed that students have positive views about the use of dictionaries for learning EFL; they prefer to use monolingual dictionaries, but they cannot truly use them because bilingual dictionaries are easier and more helpful for them in translation as well as their process of learning English language due to their low proficiency levels. The paper puts forth some recommendations and suggestions that will be helpful for using monolingual dictionaries. It concludes by focussing on the problems in handling monolingual dictionaries.
\end{abstract}

Key words: Bilingual, Dictionaries, EFL Context, Monolingual

\section{INTRODUCTION}

Inadequate knowledge of vocabulary on the part of learners can cause problem in the acquisition of foreign language (Asgari \& Mustapha, 2011). The importance of dictionaries is indispensable as far as the acquisition of vocabulary is concerned (Lew, 2011) in case of learning of English as a Foreign language (EFL) or learning English as a Second Language (ESL). Therefore, the use of dictionaries has a pivotal role to play not only in the use of language but also in its' learning as well.

Dictionaries help students in getting a lot of information about words and their proper usage (Aleeva, \& Safiullina, 2016). Hence, the importance of dictionaries cannot be underestimated as far as the learning of EFL or ESL is concerned. Koca, Pojani and Jashari-Cicko (2014) expressed that learners must possess a wide range of vocabulary and a good lexical competence to comprehend and learn English. Pousi (2010) emphasized a lot on the acquisition of vocabulary for learning of a foreign language and its skills. Most teachers and students unanimously agree on the fact that "the main purpose of a dictionary is to present or at least reduce the conflicts which arise from lexical deficit (Hartman, 1987). Therefore, the learning of vocabulary is a key to learning a language. One cannot make progress in his learning of a language without a good store of vocabulary at hand.

Chan (2011) makes a comparison between types of dictionaries such as monolingual and bilingual dictionaries. However, there is also a lot of emphasis placed on the use of monolingual dictionaries for learning of the foreign language. It is also a fact that many students preferred to use bilingual dictionaries instead of monolingual dictionaries for the learning of EFL (Loucky, 2003) since they find bilingual dictionaries very easy. The main purpose of this study is to highlight the preference for the kind of dictionary in EFL or ESL context. Monolingual dictionaries are preferred for learning of foreign language while bilingual dictionaries are given more importance for learning of translation (Ayupova, 2014) studies. The present research will also point out the kind of dictionaries used by Saudi students for learning EFL. 


\section{LITERATURE REVIEW}

\section{Choice of Dictionaries by EFL learners}

Researchers like Liu (2014) favor the use of dictionaries, either bilingual dictionaries or monolingual dictionaries based on the research that they make into the behaviors of dictionary users. The choice of the use of dictionary depends on the students' inclination. Dictionaries are the most important tool for the learning of vocabulary as far as EFL or ESL is concerned. A dictionary is such a teaching tool which helps in reading comprehension and vocabulary learning (Zelinskiy 2014; Rezaei \& Davoudi,2016). Besides this, the use of dictionary is generally of great help for learning a language and its' skills. However, the major problem is the selection of a dictionary. What should be considered to make the selection of a dictionary? Should the proficiency of the students be thought of while making the selection of a dictionary? Baxter (1980) says that high frequency words receive appropriate treatment in monolingual dictionaries than other varieties of dictionaries because they are extensively used in English textbooks. Hayati (2005) opined that monolingual dictionaries do not only focus the definitions but also other important aspects of vocabulary as well. The present study will point out the fact that learners who are proficient in English tend to use monolingual dictionaries than bilingual ones.

Monolingual dictionaries are used to promote the fluency through definition of vocabulary in accordance with the context. Monolingual dictionaries are useful in acquiring language proficiency (Nguyen Trong Nhan \& Thi Lai, 2012).). Hartman (1992) says that proficient users can only benefit from monolingual dictionaries. The use of a monolingual dictionary has a lot of reliance on a target language and it provides ample opportunities for the production of language activities. Underhill (1984) suggested that the monolingual dictionaries compel students to think in the target language and help them to get rid of translation habits, and also enable them to make questions and answer them on their own.

Conversely, bilingual dictionaries emphasized on word translation equivalents which are not good in all contexts and give birth to confusions and doubts. Learners cannot be proficient in language learning if they rely on bilingual dictionaries in learning a foreign language. Ard (1982) proposed that bilingual dictionaries become the cause of errors. However, Hayati (2005) said that the bilingual dictionaries assist students in getting concrete answers whereas monolingual dictionaries compel students to guess or predict the meaning and henceforth puzzle them. Thomson (1987) recommends bilingual dictionaries because he says that all the details given in monolingual dictionaries are also provided in the bilingual dictionaries as well. Further to this, he thinks that a bilingual dictionary is more valuable than the monolingual dictionary. Monolingual dictionaries on the other hand provide a very detailed description that might not give the intended meaning. Tulgar (2017) suggests that the use of monolingual dictionaries help the users to think in the target language and students feel uneasy when they use them as compared to bilingual dictionaries. However, things are not easy and quick to learn as far as the use of monolingual dictionaries is concerned.
Lew (2004) pointed out that monolingual dictionaries have more limitations because their definitions are more complicated and difficult to be comprehended due to the grammatical structure. Further to this, Lew and Doroszewka (2009) said that bilingual dictionaries form translation habits in the learners and restrict them from thinking directly in the foreign language. Monolingual dictionaries involve complexity in learning a foreign language while bilingual dictionaries are a hindrance in the way of acquiring proficiency of the language. Bilingual dictionaries also resist learners in developing their academic skill like paraphrasing, and also give very little information about semantically related words like synonyms and antonyms, etc. Atkins (1998) proposed that each EFL dictionary is different from the other on the ground of different eleven points. Despite all this, EFL learners are more willing to use bilingual dictionaries than the monolingual ones as they think of bilingual dictionaries as easy and time- saving ones.

The most difficult thing for EFL learners in using the monolingual dictionaries is the language of dictionaries. It is not easy for language learners to learn vocabulary in one go. Monolingual dictionaries have very difficult definitions and symbols about the words which give birth to complications and difficulties for less proficient students to understand them. On the contrary, bilingual dictionaries have a very easy language which contain straight forward and less complicated definitions which encourage the EFL learners to adopt them instead of monolingual dictionaries.

\section{Use of Dictionaries for Language Learning}

Language learners' use of dictionaries has been analyzed from different angles. An eminent researcher, such as Pousi (2010), focused on the accuracy of learners through dictionary. It has also effects on the comprehension of reading (Knight, 1994). Tomaszczyk (1979) was the first researcher in history who took the initiative to look into the use of dictionary by non-native English speakers. He published a study about a Polish university's students. The students liked bilingual dictionaries more than monolingual dictionaries. The results of the study revealed the fact that majority of the learners preferred to use bilingual rather than monolingual dictionaries.

There was a similar kind of study found by Bejoint (1981) on the use of monolingual dictionaries by French EFL learners. Opposite to Tomaszczyk, $17 \%$ of the participants had liking for bilingual dictionaries. Additionally, there are some other studies like Ryu (2005) who focused on the training as far as the use of dictionary is concerned. Pousi (2010) pointed in his study that the untrained users of dictionary performed their matters of comprehension and production in bilingual dictionaries than through the monolingual dictionaries. It is therefore highlighted that the use of dictionary is easier and more comprehensive if one has the artifice to use a dictionary in his learning of a language. Schmit (2002) also proposed about the Japanese EFL learners that $85 \%$ of the Japanese EFL learners preferred to use bilingual dictionaries and only $15 \%$ were in favor of monolingual dictionaries. 
Further to this, Ali (2012) cited in Hayati (2005) who made a comparison between the impact of bilingual and monolingual dictionaries on comprehension among the Iranian EFL learners studying at Shahid Chamran Univeristy of Ahwaz. The results of the study revealed the fact that the use of bilingual dictionary during the reading can help the intermediate students to comprehend in a far effective way than the reading practices without the use of monolingual dictionary. Bilingual dictionaries proved to be an equally important pedagogical tool in comparison to monolingual dictionaries as far as the comprehension of reading among EFL learners was concerned. None of the types of dictionaries seemed to be superior. In the light of the results of the previous studies, it is aimed that the uses of both monolingual and bilingual dictionaries are equally important, but it is the bilingual dictionaries which is the best option for beginners than the advance level students. The study will set to explore the perceptions and attitudes of secondary school students towards the use of dictionary in EFL contexts especially on the part of secondary school students in Kingdom of Saudi Arabia.

\section{Objectives and Research Questions}

The study will explore the perceptions and attitudes of the learners of the Secondary School Students around Kingdom on the following questions as far as the use of dictionaries in learning a foreign language is concerned:

1. What are the students' perceptions about the use of dictionary?

2. What kind of dictionary is used by the learners?

3. Which kind of dictionary is preferred by the EFL learners?

4. How can dictionaries be helpful to the students in their learning?

\section{METHODS}

Sequential mixed method was used to carry out the current study. Choice of Sampling, data collection and data analysis methods are presented in this section.

\section{Samples and Sampling}

This section presents the sampling methods followed in selecting the samples and cases for the current study.

\section{Sampling of quantitative data}

The present study investigates into the perceptions of the learners about the use of dictionary. The target population of the study is the secondary level students of two governmental secondary school of Zulfi, KSA. There were 99 questionnaires distributed among all the secondary school students of the two schools, but only 92 participants responded to the questionnaires. Permission was obtained from the schools' authorities for participation of the students in the study. Saudi Arabia is a gender-based society where both genders are taught separately. Therefore, all the population of the research were male students. They were all homogeneous by the virtue of having one language and culture. The data was collected through purposive sampling technique.

\section{Sampling of qualitative data}

The questionnaire is followed by semi structure interviews of EFL teachers to support the findings of the questionnaire. There were nine teachers who participated in the semi-structured interviews. They were all Saudis. The data was collected through purposive sampling technique.

\section{Data Collection}

This section presents the instruments and data collection procedures.

\section{Quantitative data collection}

The quantitative data was administered by a gate keeper. The data was collected within a time frame of one week. All the students were beginners since the level of the students in English is very low throughout the kingdom of Saudi Arabia. The questionnaire is divided into two sections. The first section deals with the demographic information while the second part concerns with the perceptions of the students. The items in the second part have five points Likert scale. The questionnaire was adapted from Ali (2012) with slight changes recommended by the experts in the filed. Appendix 1 shows the questionnaire. The questionnaire was piloted before the collection of data to avoid ambiguities and irrelevancies. The validity of the questionnaire was established through getting the second opinions of the experts. Cronbach Alpha was used to check the internal reliability of the questionnaire. The questionnaire had a high coefficient value of.81. The data was analyzed using percentages and frequencies.

The questionnaire was distributed electronically with the help of a gate keeper among students of the two government secondary schools. The questionnaire was sent to the students through WhatsApp. Permission was obtained from school authorities before the data collection was conducted. The questionnaire was sent to experts to ensure its content validity. Some modifications were made in the questionnaire according to the recommendations of the experts before its' distribution. It took a week to gather all data electronically.

\section{Qualitative data collection}

Instrument of qualitative data was semi-structured interviews. The interviews had open-ended questions (Appendix 2) based on the literature of the study. The qualitative portion of the study gained further information that the quantitative could not disclose. The objective of the interview was to probe deeply into perceptions of teachers about the use of dictionaries in the classrooms by their students. The interviews took place through emails. These interviews were coded and analyzed. Following are the interview questions together with probes:

1. What do you know about different kinds of dictionaries?

i). How is dictionary helpful in teaching a language? (probe)

2. Do you use a dictionary?

i). Which dictionary do you use? (probe)

3. Do you advise your students to use dictionary? 
Table 1. Quantitative Findings of the study

\begin{tabular}{|c|c|c|c|c|c|c|}
\hline Items & $\begin{array}{c}\text { Strongly } \\
\text { Disagree (SD) }\end{array}$ & $\begin{array}{c}\text { Disagree } \\
\text { (D) }\end{array}$ & $\begin{array}{c}\text { Neutral } \\
\text { (N) }\end{array}$ & $\begin{array}{l}\text { Agree } \\
\text { (A) }\end{array}$ & $\begin{array}{c}\text { Strongly } \\
\text { Agree (SA) }\end{array}$ & $\begin{array}{c}\text { Cumulative } \\
\text { percent (Agree) }\end{array}$ \\
\hline \multicolumn{7}{|c|}{ Monolingual dictionaries are easy to use } \\
\hline Frequency & 5 & 13 & 28 & 28 & 18 & \\
\hline Percentage & 5.1 & 13.1 & 28.3 & 28.3 & 18.2 & 80.4 \\
\hline Valid Percentage & 5.4 & 14.1 & 30.4 & 30.4 & 19.6 & \\
\hline \multicolumn{7}{|c|}{$\begin{array}{l}\text { Monolingual dictionaries are helpful for } \\
\text { thinking in English }\end{array}$} \\
\hline Frequency & 3 & 12 & 35. & 26 & 16 & \\
\hline Percentage & 3.0 & 12.1 & 35.4 & 26.3 & 16.2 & 82.6 \\
\hline Valid Percentage & 3 & 13.0 & 38 & 28.3 & 17.4 & \\
\hline \multicolumn{7}{|c|}{$\begin{array}{l}\text { Monolingual dictionaries are better } \\
\text { options for learning a foreign language }\end{array}$} \\
\hline Frequency & 3 & 13 & 27 & 28 & 21 & \\
\hline Percentage & 3.0 & 13.1 & 27.3 & 28.3 & 21.2 & 77.2 \\
\hline Valid Percentage & 3.3 & 14.1 & 29.3 & 30.4 & 22.8 & \\
\hline \multicolumn{7}{|c|}{$\begin{array}{l}\text { Bilingual dictionaries have clear } \\
\text { definitions }\end{array}$} \\
\hline Frequency & 3 & 6 & 28 & 35 & 20 & \\
\hline Percentage & 3.0 & 6.1 & 28.3 & 35.4 & 20.2 & 78.3 \\
\hline Valid Percentage & 3.3 & 6.5 & 30.4 & 38 & 21.7 & \\
\hline \multicolumn{7}{|c|}{$\begin{array}{l}\text { I can easily understand things in my first } \\
\text { language }\end{array}$} \\
\hline Frequency & 3 & 2 & 24 & 24 & 39 & \\
\hline Percentage & 3.3 & 2.0 & 24.2 & 24.2 & 39.4 & 57.6 \\
\hline Valid Percentage & 3.3 & 2.2 & 26.1 & 26.1 & 42.4 & \\
\hline \multicolumn{7}{|c|}{$\begin{array}{l}\text { Bilingual dictionaries are very quick for } \\
\text { searching }\end{array}$} \\
\hline Frequency & 7 & 7 & 29 & 22 & 27 & \\
\hline Percentage & 7.1 & 7.1 & 29.3 & 22.2 & 27.3 & 70 \\
\hline Valid Percentage & 7.6 & 7.6 & 31.5 & 23.9 & 29.3 & \\
\hline \multicolumn{7}{|c|}{ Bilingual dictionaries are time saving } \\
\hline Frequency & 2 & 7 & 28 & 31 & 24 & \\
\hline Percentage & 2.0 & 7.1 & 28.3 & 31.3 & 24.2 & 73.9 \\
\hline Valid Percentage & 2.2 & 7.6 & 30.4 & 33.7 & 26.3 & \\
\hline
\end{tabular}

i) Which dictionary you recommend for your students? (probe)

4. How are your students at learning a language?

i) Which dictionary is easy for them? (probe)

Interview questions were sent to teachers through two gatekeepers. All the participants willingly participated in the study. Participants answered the questions electronically through emails. The validity of the questionnaire was obtained through triangulation.

\section{Data Analysis}

Descriptive statistical methods were used for analyzing the quantitative data. Thematic analysis of all the interviews was conducted to analyze the qualitative data.

\section{RESULTS}

Presentation of resulits is divided into two sections. The first section reflects the quantitative results while the second reports the qualitative results.

\section{Analysis of Quantitative Data}

The findings of the study (see Table 1) reveal that students have positive perceptions towards the utility of dictionaries in learning a foreign language. In response to the question: What are their perceptions about the use of dictionaries? A cumulated $82 \%$ of the participants favored the use of monolingual dictionaries for thinking in English. Another cumulated $78 \%$ of the participants expressed positive feelings for bilingual dictionaries because of their clear definitions. 
Table 2. Qualitative Findings of the Study

\begin{tabular}{|c|c|c|}
\hline Category & Meaning & Evidence from the data \\
\hline Types of Dictionaries in use & Kinds of Dictionaries used by learners & $\begin{array}{l}\text { I believe } 95 \% \text { of my students would go for English } \\
\text { to Arabic dictionaries. } \\
\text { I try to get them to use English to English } \\
\text { dictionaries, but they insist in using Arabic to } \\
\text { English ones } \\
\text { They mainly prefer English to Arabic, because they } \\
\text { are always in hurry to get the meaning. }\end{array}$ \\
\hline Suggested dictionaries use & $\begin{array}{l}\text { When, where, and which dictionaries } \\
\text { to be used }\end{array}$ & $\begin{array}{l}\text { I advise my students to use the Dictionaries which } \\
\text { are available in smart phones such as dictionary-box } \\
\text { Arabic-English and English-English Dictionary. } \\
\text { Majority of my students regularly use the online } \\
\text { dictionary, because it's faster and easier. }\end{array}$ \\
\hline Usefulness of Dictionaries & Benefits of dictionaries & $\begin{array}{l}\text { They mainly prefer English to Arabic, because they } \\
\text { always in a hurry to get the meaning. } \\
\text { They insist in using Arabic to English ones. } \\
\text { Probably because they find it easier, plus they aren't } \\
\text { passionate enough to improve their English which } \\
\text { makes it challenging to get them to learn }\end{array}$ \\
\hline
\end{tabular}

There is also a cumulated $57 \%$ of the participants of the study who suggested that they can better understand in their own language. The results also reveal a cumulated $71 \%$ of the participants who understand that people who have a good knowledge of English prefer to use monolingual dictionaries. Also, another cumulated $80 \%$ of the students are in favor of training for the better use of dictionaries. In answer to the question what kind of dictionary is used by learners? We also find a cumulated $62 \%$ of the students who say that they use monolingual dictionaries while another cumulated $83 \%$ of the students showed their likeness to use bilingual dictionaries. In answer to preference of the kind of dictionary: we have also a cumulated $55 \%$ of the students who preferred to use monolingual dictionary. In reaction to the help a monolingual dictionary offers, we also find a cumulated figure of $71 \%$ of the participants who think that monolingual dictionaries are helpful for students to think in the target language who have a better knowledge of English whereas bilingual dictionaries are a good option for those who are not good at English. We also get a cumulated 70\% of students' opinions who say that bilingual dictionaries are helpful in searching words quickly. Another cumulated figure of $73 \%$ of students think that bilingual dictionaries help them because they are time saving.

\section{Perception about monolingual dictionaries helpfulness in thinking}

Students perception about the item: Monolingual dictionaries are helpful for thinking in English can be described as follows: There were $17 \%$ of the participants who strongly agreed to the item. Another $28 \%$ students agreed to the statement that monolingual dictionaries helpfulness in thinking in English whereas 35\% participants remained neutral to the item. Also, there were $13 \%$ of the students who disagreed, and $3 \%$ participants who disagreed strongly to the question.

\section{Participants perception about clear definitions of bilingual dictionaries}

Regarding participants thinking about the item: Bilingual dictionaries have clear definition, we have the following results: There were $27 \%$ of the participants who strongly agreed to the statement while $38 \%$ of the students agreed to the item. There were another $30 \%$ of participants who were neutral to the statement whereas $3 \%$ participants strongly disagreed and 6 percent of the students disagreed to the item.

\section{Proficient students preference of monolingual dictionaries over bilingual dictionaries}

Students responses to the item 'People who speak English well prefer to use monolingual dictionaries than bilingual dictionaries' can be recorded such as: There are 28 percent of students who strongly agreed to the item, and also 28 percent of the participants strongly agreed to the statement while there were 33 percent of the students who were neutral to the statement while 6 percent disagreed while 3 percent strongly disagreed to the item.

\section{Students' viewpoint about better understanding of things in $\mathrm{LI}$}

In answer to the item 'I can understand things in my first language', there were $42 \%$ of the students who strongly agreed to the item while $26 \%$ of the participants agreed to the statement. There were another 26 percent of students who were neutral in their response to the question whereas 3 percent of the students strongly disagreed, and 2 percent agreed to the item.

\section{Qualitative Data Analysis}

The researchers interviewed some secondary schools' teachers (see Table 2) about their point of view for the questions in Appendix 2. During this interview the researchers observed the following: 


\section{Importance of dictionaries for teachers}

Most of the interviewees stated that dictionaries are very important and helpful in teaching. Furthermore, regarding the importance of dictionaries for teachers in teaching, it is believed that dictionaries are the main part in this matter, and they are very helpful in teaching for both teachers and students.

\section{Importance of dictionaries for students}

The teachers asserted that dictionaries are so important as they help them:

1. look up for the transcriptions of words

2. look up and find the meaning that they will never forget.

3. find pronunciations of words.

4. provide examples.

5. find the kinds of words and explanations of them

6. students can expand their resources and read more and more new vocabulary and definitions.

\section{Recommended dictionaries}

The dictionaries that most of the teachers advised their students to use were Oxford and Longman Dictionaries. A few also advised using Cambridge Dictionary and Mariam Webster's Dictionary. Finally, online dictionaries were also recommended by a few although many students prefer them.

\section{Students' preference to use bilingual or monolingual dictionaries}

The teachers reported that students prefer English-Arabic dictionaries, thinking that they will be easy to use. One participant believed that $95 \%$ of his students would go for English to Arabic dictionaries. The teachers argued that they did their best to get their students to use English to English dictionaries, but the students insisted on using Arabic to English ones. One of the teachers explained that most of the students lacked the desire to learn, which could be the reason why they preferred to use English to Arabic. Another teacher stated that the students had not reached the level so that they could use monolingual dictionaries; therefore, they used English-Arabic dictionaries. A final reason which was mentioned by one of the teachers for students' preference to use bilingual dictionaries was that they were always in hurry to look up the meaning. Only one teacher stated that his students sometimes used English to English dictionaries.

\section{Students' mastery in using dictionaries}

It was pointed out that only some excellent students had mastery in using dictionaries, but the students generally know how to use them. There were also teachers who stated that some of the students lack the skill. Finally, one of the teachers was aware that some good students used English to English as well as English to Arabic dictionaries; they used the former to look up words and tried to guess the meaning; after that, they used the latter to understand the Arabic translation.

\section{Students' regularity and irregularity in using dictionaries}

One of the teachers answered that majority of his students regularly use on-line dictionaries, they are easier and faster. Another participant argued that his students regularly use dictionaries which give them meanings directly. One of the teachers said that he advises his students about the use of dictionaries which can be available in their smart phones and should be both English to Arabic and English to English. $\mathrm{He}$ also pointed that his students are gradually developing in their use of dictionary. Another participant responded that he advised his students to use English to English dictionaries, but they don't like to use monolingual dictionaries rather they prefer to use bilingual ones because they are not passionate enough to improve their English. The researcher observed from the teachers' responses the students regularly use dictionaries, but they prefer to use bilingual dictionaries instead of monolingual dictionaries for their low level of proficiency.

\section{DISCUSSION}

In the light of the results, it can be said that Saudi students favor bilingual dictionaries because they are easy and straightforward as compared to monolingual dictionaries There is a cumulated $83 \%$ of the participants of the questionnaire of this study who expressed their likeness for bilingual dictionaries. A cumulated $55 \%$ of the participants of the questionnaire of the present study preferred to use monolingual dictionaries because they help them to think in English, but they emphasized on the importance of training for a good use of dictionary.

The findings of the studies support the claim of the hypothesis that monolingual dictionaries are helpful in teaching English (Ali, 2012; Talgar, 2017). Because monolingual dictionaries help students in thinking in English which can improve their proficiency. It is also emphasized that students need training for their use of dictionaries.

Pousi (2010) hypothesizes that bilingual dictionaries are good for comprehension in the case of untrained learners. Bilingual dictionaries are easy to be used. Schmit (2002) also proposed in his study in which $85 \%$ learners favored bilingual dictionaries for learning a foreign language. Lew and Doroszewka (2009) also favored the use of bilingual dictionaries for translation. But bilingual dictionaries also obstruct learners to think in a foreign language.

The interviews of the teachers were based on four questions. The interviews were taken from English teachers teaching in different governmental secondary schools of Zulfi. Teachers were asked to give responses about their perceptions regarding the use of dictionaries by secondary school students. Teachers responses were collected through two gatekeepers so as to evade the chance of being biased.

Eight out of nine teachers $(88 \%)$ favored the use of bilingual dictionaries in response to the question: "Do you advise your students to use a dictionary?" followed by the probe "which dictionary do you recommend for your students?" They told that they advise their students to use bilingual dictionaries for it is easy for them to use them since they are not good at English. 
In an answer on the level of the students, one the teacher said that $95 \%$ of his students are lower than average in learning English language and they are not even passionate in their learning. Maybe, the problem is demotivation. They take learning of English as a big challenge for them. This teacher also proposed that it is hard for the students to use English to English dictionaries because of their low level in English.

Almost all the teachers who took part in the interviews supported the use of dictionaries for learning a foreign language. They said that it is very helpful for them in overcoming the different stages of learning the foreign language. They can use dictionaries such as for knowing the meaning, pronunciation and translation etc.

\section{CONCLUSION}

In general, the results of the study are in line with previous studies by the researchers (Ali, 2012; Lew, 2004; Pousi, 2010; Taglar, 2017). The results are particularly very close to Ali (2012). There are 71 percent of the participants who favor the statement the students proficient in English prefer to use monolingual dictionaries in learning EFL. The findings of the study will extend our knowledge about the use of dictionaries for learning EFL. Again, there are 82 percent of the learners in the present study who endorsed the use of monolingual dictionaries for thinking in English.

The findings of the interviews verified the results obtained from the questionnaires. The interviews were conducted to endorse the perceptions and the opinions of the students about their use of dictionaries in the process of learning EFL. There are 88 percent of the participants who think that bilingual dictionaries are easy to be used by those who are not good at English.

To conclude, the study is an advancement towards students' perception about the use of dictionary in learning EFL. It particularly focusses on the perceptions and behaviors of Saudi students towards the use of dictionary. They prefer to use monolingual dictionaries for learning EFL, but they are more likely to use bilingual dictionaries that are comparatively easier to understand since they have the use of their mother tongue. The study proposes the following points as far as the use of dictionary, or familiarity with the nature of dictionaries for learning on the part of Saudi students is concerned. The study brings forward the following recommendations:

- Saudi students should be encouraged to use monolingual dictionaries instead of bilingual dictionaries. As the monolingual dictionaries can not only enhance their thinking skill but also their proficiency as well. This perception is endorsed by the cumulated $82 \%$ of the participants of the quantitative findings of this study. They should be advised not to translate vocabulary in their first language as it can obstruct their fluency in learning a foreign language.

- To encourage the use of monolingual dictionaries, the students should be taught dictionary skill during their classes. A cumulated $80 \%$ of the participants of the survey questionnaire endorsed the need of training for the use of dictionary on the part of students. The stu- dents should also be encouraged to find out the meaning and definition of words from a monolingual dictionary so as to think in the target language for learning it fast.

\section{REFERENCES}

Aleeva, G. K., \& Safiullina, G. R. (2016). Using Dictionaries in Teaching English as A Foreign Language. Retrieved from: https://files.eric.ed.gov/fulltext/EJ1114632.pdf.

Ali, H. I. H. (2012). Monolingual Dictionary Use in an EFL Context. Retrieved from http://www.ccsenet.org/journal/index.php/elt/article/view/18348/12145.

Ard, J. (1982). The use of bilingual dictionaries by ESL students while writing. Retrieved from https://doi. org/10.1075/itl.58.01 ard.

Asgari, A., \& Mustapha, G. B. (2011). The Type of Vocabulary Learning Strategies Used by ESL. Students in University Putra Malaysia. Retrieved from http://citeseerx.ist.psu.edu/viewdoc/download?doi=10.1.1.1031.5110\&rep=rep1\&type $=$ pdf.

Atkins, B. T. S. (ed.). (1998). Using Dictionaries: studies of dictionary use by language learners and translators. Niemeyer: Tübingen.

Ayupova R. A. (2014). Macrostructural parameters of unilingual Russian phraseological dictionaries. Life Science Journal, 11(6), 511-515. Retrieved from http:// www.lifesciencesite.com/1sj/life 1106/073_24746li fe110614_511_515.pdf

Baxter, J. (1980). The dictionary and vocabulary behavior: A single word or a handful? TESOL Quarterly, 14(3), 325-336.

Béjoint, H. (1981). The foreign student use of monolingual English dictionaries: A study of language needs and reference skills. Applied Linguistics, 2(3), 207-222.

Celce-Marcia, M. (2001). Teaching English as a second or foreign language ( $3^{\text {rd }}$ ed.). Boston Massachusetts: Heinel \& Heinel.

Chan, A. (2011). Bilingualized or monolingual dictionaries? Preferences and practices of advanced ESL learners in Hong Kong. Language, Culture and Curriculum, 24(1), 1-21. DOI: 10.1080/07908318.2010.510196

Crystal, D. (1987). The Cambridge Encyclopedia of Language. Oxford: Oxford University Press.

Hartmann, R. R. K. (1987). Four perspectives on dictionary use: a critical review of research methods. In A. Cowie, A. P. (ed.), The dictionary and the language learner: Papers from the EURALEX seminar at the University of Leeds, I-3 April 1985 (pp. 1 1-28). Tubingen. Max Niemeyer Verlag: 11-28.

Hayati, A. M. (2005). A comparative study of using bilingual and monolingual dictionaries in reading comprehension of intermediate EFL students. The Reading Matrix Journal, 5(2), 61- 66 .

Knights, S. (1994). Dictionary use while reading: The effects on comprehension and vocabulary acquisition for students of different verbal abilities. The Modem Language Journal, 78(3), 285-299. http://dx.doi. org/10.1111/j.1540-4781.1994.tb02043.x

Koca, S., Pojani, V., \& Jashari-Cicko, A. (2014). Dictionary 
use by EFL university students a case-study at Korça University. Mediterranean Journal of Social Sciences, 5(19), 74-83. https://doi.org/10.5901/mjss.2014.v5n19p74.

Lew, R. (2011). Studies in dictionary use: recent developments. International Journal of Lexicography, 24(1), 1-4. doi:10.1093/ij1/ecq044

Lew, R. (2004). Which dictionary for whom? Receptive use of bilingual, monolingual and semi-bilingual dictionaries by Polish learners of English (Published PhD thesis), Motivex Poznan, Poland.

Lew, R. \& Doroszewka, J. (2009). Electronic dictionary entries with animated pictures: Lookup preferences and word retention. Int $J$ Lexicography, 22(3), 239-257. DOI: https://doi.org/10.1093/ij1/ecp022

Liu, L. (2014). The integration of dictionary use strategy training into basic English class. Theory and Practice in Language Studies, 4(10), 2138-2143. https://doi. org/10.4304/tpls.4.10.2138-2143.

Loucky, J. P. (2003). Using computerized bilingual dictionaries to help maximize English vocabulary learning at Japanese Colleges. Retrieved from https://doi.org/10.4304/ tpls.4.10.2138-2143.

Maingay, S., \& Rundell, M. (1987). Anticipating learners' errors: Implications for dictionary writers. In A. Cowie (Ed.), The dictionary and the language learner: Papers from the EURALEX seminar at the university of Leeds, 1-3 April 1985 (pp. 128-35). Tiibingen: Max Niemeye Verlag.

Nhuyen Trong Nhan \& Ho, Thi Lai (2012). The enhancement of learner autonomy and the growth of English language proficiency. Language in India, 12, 427-439. Retrieved from http://www.languageinindia.com/april2012/nguyenproficiency.pdf.

Pousi, B. (2010). Training in dictionary use: A teaching intervention in a $9^{\text {th }}$ grade EFL classroom in Finland. Unpublished B.A thesis, University of Jyvaskyla.

Rezaei, M., \& Davoudi, M. (2016). The Influence of Electronic Dictionaries on Vocabulary Knowledge Extension. Journal of Education and Learning, 5(3), 139-148.

Ryu, J. (2005). Dictionary use by Korean EFL college students. Language and Information Society, 7, 83-114.

Schmitt, N. (2002). An introduction to applied linguistics. London: Hodder Arnold Press.

Thompson, G. (1987). Using bilingual dictionaries. ELT Journal, 41, 282-286.

Tomaszczyk, J. (1979). Dictionaries: users and uses. Glottodidactica, 12, 103-119.

Tulgar, T. T. (2017). Dictionary Use of Undergraduate Students in Foreign Language Departments in Turkey at Present. Universal Journal of Educational Research 5(12B), ujer, 2017.051406. https://files.eric.ed.gov/fulltext/EJ1165475.pdf.

Underhill, A. (1989). Using your dictionary. Oxford: Oxford University Press.

Zelinskiy, S. (2014). Electronic Dictionaries and pocket translators. Retrieved from http://infoenglish.info/ publ/1-1-0-27. 


\section{APPENDIX 1}

Appendix 1. Questionnaire on learners' perceptions of monolingual dictionaries in learning english as a foreign language

\begin{tabular}{|c|c|c|c|c|c|c|}
\hline Sr. \# & Questionnaire & & & & & \\
\hline 1 & Age & & & & & \\
\hline 2 & Gender & & & & & \\
\hline 3 & Level of learning & & & & & \\
\hline 4 & Kind of learner & & & & & \\
\hline 5 & What is your first language? & & & & & \\
\hline 6 & Do you use dictionary & & & & & \\
\hline 7 & What kind of dictionary you use & & & & & \\
\hline 8 & Which kind of dictionary do you prefer? & & & & & \\
\hline 9 & I like to use bilingual dictionaries & SD & $\mathrm{D}$ & $\mathrm{N}$ & $\mathrm{A}$ & SA \\
\hline 10 & Monolingual dictionaries are easy to use & & & & & \\
\hline 11 & $\begin{array}{l}\text { Monolingual dictionaries are helpful for thinking in } \\
\text { English }\end{array}$ & & & & & \\
\hline 12 & $\begin{array}{l}\text { Monolingual dictionaries are better options for } \\
\text { learning a foreign language }\end{array}$ & & & & & \\
\hline 13 & Bilingual dictionaries have clear definitions & & & & & \\
\hline 14 & I can easily understand things in my first language & & & & & \\
\hline 15 & Bilingual dictionaries are very quick for searching & & & & & \\
\hline 16 & Bilingual dictionaries are time saving & & & & & \\
\hline 17 & $\begin{array}{l}\text { Dictionaries can be used in a good way accompanied } \\
\text { by training }\end{array}$ & & & & & \\
\hline 18 & $\begin{array}{l}\text { People who speak English well prefer to use } \\
\text { monolingual than bilingual dictionaries }\end{array}$ & & & & & \\
\hline
\end{tabular}

\section{APPENDIX 2}

\section{Faculty Interview Protocol}

Institute:

Name:

Highest Degree:

1. What do you know about different kinds of dictionaries?

How is dictionary helpful in teaching a language?

2. Do you use a dictionary?

Which dictionary do you use?

3. Do you advise your students to use dictionary?

Which dictionary do you recommend for your students?

4. How are your students at learning English?

Which dictionary is easy for them?

Please send the answers to my E-mail: safwanabbasi2010@yahoo.com 